\title{
Article \\ Investigation of PEEK Lined Pads for Tilting-Pad Journal Bearings
}

\author{
Steven Chatterton ${ }^{1, *(\mathbb{D}}$, Edoardo Gheller ${ }^{1}$, Andrea Vania ${ }^{1}$, Paolo Pennacchi ${ }^{1}\left(\mathbb{D}\right.$ and Phuoc Vinh Dang ${ }^{2} \mathbb{C}$ \\ 1 Department of Mechanical Engineering, Politecnico di Milano, Via La Masa 1, I-20156 Milan, Italy; \\ edoardo.gheller@polimi.it (E.G.); andrea.vania@polimi.it (A.V.); paolo.pennacchi@polimi.it (P.P.) \\ 2 Department of Mechanical Engineering, The University of Danang-University of Science and Technology, \\ 54 Nguyen Luong Bang Street, Danang 550000, Vietnam; dpvinh@dut.udn.vn \\ * Correspondence: steven.chatterton@polimi.it
}

Citation: Chatterton, S.; Gheller, E.; Vania, A.; Pennacchi, P.; Dang, P.V. Investigation of PEEK Lined Pads for Tilting-Pad Journal Bearings. Machines 2022, 10, 125. https:// doi.org/10.3390/machines10020125

Academic Editor: Gianni Campatelli

Received: 18 January 2022

Accepted: 9 February 2022

Published: 10 February 2022

Publisher's Note: MDPI stays neutral with regard to jurisdictional claims in published maps and institutional affiliations.

Copyright: (C) 2022 by the authors. Licensee MDPI, Basel, Switzerland This article is an open access article distributed under the terms and conditions of the Creative Commons Attribution (CC BY) license (https:// creativecommons.org/licenses/by/ $4.0 /)$.
Abstract: Tilting-pad journal bearings are widely used in industry to support rotating shafts due to their high dynamic performance. The operating limits of these bearings are mainly represented by the maximum permissible temperature of the lined materials of the pads and by the minimum thickness of the oil-film under which mixed lubrication can occur. The current trend in bearing development sees the adoption of innovative materials in the production of the pads, that provide higher load capacity, higher temperature capability and greater fatigue resistance. In this paper, the static characteristics of bearings lined with different materials, will be investigated. The temperature distribution in the bearing will be evaluated by means of a full 3D thermal model whereas the deformation of the pads will be evaluated by means of a finite element model. At the end, the permissible operating range in terms of load and speed will be defined for each material by considering the limits on the maximum temperature, permissible mechanical stress and minimum oil-film thickness.

Keywords: tribology; tilting-pad journal bearing; lined-pad; PEEK; white metal; thermo-elastohydrodynamic lubrication; thermal model; pad deformation; lining thickness

\section{Introduction}

Oil-film bearings are widely used in industry to support rotating shafts especially when diameters, loads and operating speeds are not compatible with the use of simple rolling elements bearings. Nowadays, in modern rotating machines such as compressors, gas or steam turbines and large-sized generators, tilting-pad journal bearings (TPJBs) are used in most cases due to their high dynamic performance.

Although their principle of operation based on hydrodynamic lubrication is very simple, they are still extensively analyzed and studied by many researchers who have developed increasingly sophisticated mathematical models capable of describing the hidden phenomena involved in the effective functioning of the bearings [1,2].

The operating limits of these bearings are mainly represented by the maximum operating temperature of the materials used [3] and by the minimum thickness of the oil-film under which mixed lubrication can occur, with possible friction phenomena [4]. The heat developed during operation is generated in the oil-film due to the viscous shear stresses and increases as both the viscosity of the lubricant and the speed gradient in the direction of the oil-film thickness increase, i.e., as the tangential speed of the shaft or by decreasing the thickness of the oil-film.

Therefore, the state of the art of bearing models is represented by thermo-elastohydrodynamic models (TEHD) in which the temperature distribution in the entire bearing is estimated and the geometry of the oil-film is evaluated considering the deformation of the shaft-bearing system due to the mechanical and thermal stresses [5]. Accurate prediction of the TPJB performance plays an important role for ensuring satisfactory machine reliability. 
The estimation accuracy strongly depends on greater sophistication of modeling algorithms, computational methods and hardware.

Although 2D thermal models provide a good estimate of the mean temperature distribution in the lubricant film but only in the gap between shaft and pads, more complex 3D computational fluid dynamics (CFD) thermal models are capable of evaluating the temperature distribution across the entire bearing as analyzed in [6]. In particular, the most critical part for modeling is the one in correspondence of the oil inlet nozzles between two consecutive pads as discussed in [7]. In this area the hot oil coming from the previous pad and the cold oil coming from the inlet channels in the bearing are mixed. The results indicate that, in comparison with the CFD model, the conventional approach by ignoring the 3D flow physics between pads can produce considerably different bearing performances such as pressure, temperature, heat flux, dynamic viscosity, and film thickness distributions.

The reduction of the temperature can be obtained, for example, by using offset pivot pads (typical $60 \%$ offset) or simply by increasing the flow rate of the feed oil. Recently, the same authors have studied the reduction of the temperature through multivariate analyzes on the bearing geometry [8]. In this study, the variation of the assembled clearance $C_{b}$, preload factor $m_{p}=1-C_{b} / C_{p}$, pad pivot offset and flow rate between pads were considered. They concluded that the best temperature reduction can be achieved with an increase in the assembled clearance, an increase in the pivot offset and flow rate for the loaded pad. They also showed that the best temperature reduction can be achieved with bearings with different pad geometries.

The current trend in bearing development concerns on the one hand the demands of the manufacturers of rotating machines regarding energy saving, and on the other hand concerns the adoption of innovative materials in the production of the pads.

For the first aspect, the research is aimed at reducing the power dissipated by viscous friction or reducing the oil supply flow rate to reduce the installed power of the auxiliary systems. The reduction of the power loss can be easily obtained by using low viscosity oils [9], which leads as a positive consequence in the reduction of the temperature in the bearing. The experimental results show that a reduction approximately of $20-25 \%$ of the power loss using a low viscosity oil instead of the reference oil was obtained. In [10] a novel power loss reduction technique based on the TEHD-CFD model is introduced, by inserting a pocket and step in the pads, to activate cavitation in the pocket while maintaining pad stability. In this research, the power loss was reduced up to $27.3 \%$ without a load capacity loss and eccentricity ratio reduction was maximum of $52.8 \%$ for the static TPJB performance. Besides, the peak pad temperature and required supply oil flow can be decreased up to $9 \%$ and $52.8 \%$, respectively.

In recent years there has been a strong use of polymer lined pads [11] in TPJBs and to a lesser extent the use of aluminum-tin lined pads [12]. In general, these advanced coatings allow a bearing size reduction and, therefore, a reduction in power loss. This research showed that the aromatic thermosetting copolyester based coating exhibited the best wear resistance.

However, the main drawback of polymeric linings concerns the adhesion process of the material to the base metal, often protected by patents.

Standard pads are typically steel backed with a Babbitt lining (white metal). The search for new pad coating materials is still linked to the maximum operating temperature of the bearing. Generally, when the working temperature of material reaches above 30-50\% of the melting point, the material will be likely to creep [13], that is the surface movement of the lining due to a combination of high local pressure and high local temperature which exceeds the local yield strength of the material. Babbitt is a tin-antimony-copper alloy, has high load capacity and wear resistance but has a low melting point. Aluminum-tin lined pads provide higher load capacity than Babbitt pads due to higher temperature capability and greater fatigue resistance [14]. The content of the main alloying element, tin, varied from 5.4 to $11 \%$. The research showed that the low wear rates alloys are characterized with increase content of magnesium, tin, and lead in their secondary structures. It was 
also found that alloys containing more than $0.3 \% \mathrm{Mg}$ have the highest seizure load values. The lowest seizure load was observed for the alloys either without or with the minimum magnesium content.

Polyetheretherketone (PEEK) materials have higher operating temperature capabilities, show good electrical insulation, have a very-low coefficient of friction that allows to reduce torque and wear at start-up, eliminating in some cases the need for jacking oil pumps [15]. In this study, a thrust bearing with a steel pad with a 2-mm-thick hardpolymer liner was compared with that one using hard-polymer material for entirely pad whose elastic modulus is just $12.5 \mathrm{GPa}$. A novel TEHD model that considers a 3D thermal energy transport equation in the fluid film, coupled with heat conduction equations in the pads, and a generalized Reynolds equation with cross-film viscosity variation was developed. Generally, the bearing with solid hard-polymer was demonstrated to be suitable for operation at a turbulent flow condition. It shows a lower power loss and a larger film thickness; however, it requires too large supply flowrate. In comparison with a babbittedsteel pad, a hard-polymer liner isolates the pad from the fluid film and can reduces the temperature rise up to $30{ }^{\circ} \mathrm{C}(50 \%)$.

Conversely, PEEK material has a poor thermal conductivity, that is, behaving as a thermal insulator towards the base steel of the pad which remains colder than in the case of the white metal coating. This leads to a problem of misinterpreting the temperature value measured by the temperature probes [16]. Typically, at least one thermal probe is installed in the base steel part of the pad placed in the direction of the load. The measured temperature is often used as an alarm indicator in case of friction between shaft and bearing. However, the lower temperature in the steel base part of the shoe leads to a beneficial reduction of the thermal deformation of the pad itself [17]. In this study, a $500 \mathrm{~mm}$ five-pad TPJB with thin layer PEEK lined pads was investigated using TEHD model. It was found that a reduction in axial deflection can be obtained by increasing the minimum film thickness and decreasing the film thickness at the axial edges of the PEEK lined pad. The relative mechanical compression of the PEEK liner is much higher than the white metal one. However, due to the low PEEK lining thickness of $0.6 \mathrm{~mm}$ and the mechanically induced axial deflection, notable concavity in the highest pressure region was not found.

The influence of pad compliance on the dynamic characteristics of TPJBs was fully investigated by Matthew et al. [18]. They changed the pivot geometry and Young's modulus of the pad backing and pad liner to vary the pad compliance. It was concluded that the dynamic behaviors of the TPJBs at high dynamic loads were considerably depended on the pad compliance. Higher compliance of the pad backing can increase in oil-film pressure and decreases the oil-film thickness. Besides, the tapers are necessary to increase oil-film thickness in bearings with compliant liners. In order to avoid excessive deformation of the pad with ball-socket pivots and improve bearing aligning properties, authors recommended to apply a compliant liner to the line pivot pads and choose suitable elastic property of the polymer for the pad liner for the conditions of both static and dynamic performance.

Dynamic stiffness and damping coefficients of the polymer faced TPJBs at different working conditions were studied in [19]. Authors used two PEEK faced pads, one polytetrafluoroethylene (PTFE) faced pad and two entirely PEEK pads to determine the effect of variable bearing pressure, pivot features and different material of the polymer layer. From the experimental results, it was concluded that the entirely PEEK pads bearing can increase the damping and decrease the stiffness characteristics compared to pads with a PEEK lining and steel backing. Similar effects were obtained for a softer (PTFE) pad liner bearing with a steel backing. Also, the bearing with entirely PEEK pads were slightly hotter than the steel backing pads. The PEEK and PTFE surfaces backed by steel seem to provide the same thermal features.

In the literature, the behavior of PEEK-coated pads has been studied by experimental tests or by numerical simulations. Higher loads compared to Babbitt-coated pads and the resulting thermal behavior of the pads as measured by the probes in the experiments were 
tested. Warmer bearings and a lower probe temperature were observed in the experiments. The increase in operating range is generally attributed to the low friction properties of PTFE or PEEK coatings. The reasons for the increased operating range of bearing with PEEK coated pads will be examined in the paper considering the stress in the coating material. Finally, the experimental results on the thermal behavior of the bearing will be demonstrated by means of numerical simulations.

The static characteristics of bearings lined with Babbitt and PEEK will be investigated and compared and the effectiveness of PEEK material highlighted. Different coating thicknesses will be also analyzed to verify the existence of a possible optimal value of the coating thickness. The temperature distribution in the bearing will be evaluated by means of a full 3D thermal model that include the oil-films, the pads and a portion of the shaft. The deformation of the pads will be evaluated by means of a finite element model. The von Mises stresses in the lining will be evaluated and compared to the $0.2 \%$ offset yield strength of each lining material.

At the end, the permissible operating range in terms of load and speed will be defined for each material by considering the limits on the maximum temperature, permissible mechanical stress and minimum oil-film thickness.

\section{Bearing Model}

In the analysis a small TPJB with a nominal diameter of $100 \mathrm{~mm}$ has been considered. The bearing has five pads of rocker-back type with center pivot in the load-on-pad (LOP) configuration. Direct lubrication is obtained by means of oil nozzles between the pads which also maintain the tangential position of the pads themselves. The scheme of the bearing along with the bearing drawings are shown in Figure 1, whereas the nominal bearing geometry parameters are listed in Table 1 . The black dots in Figure 1 represent the pivot position, whereas the red dots represent the position of the temperature probe installed in each pad in the so-called $50-50 \%$ position, i.e., in the middle of axial and tangential directions, and at a distance of $2 \mathrm{~mm}$ under the pad lining.

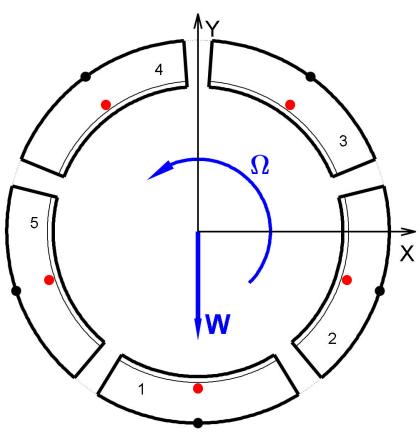

(a)

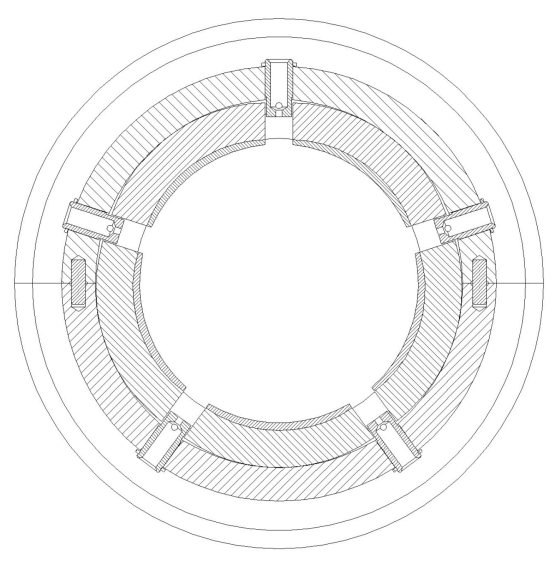

(b)

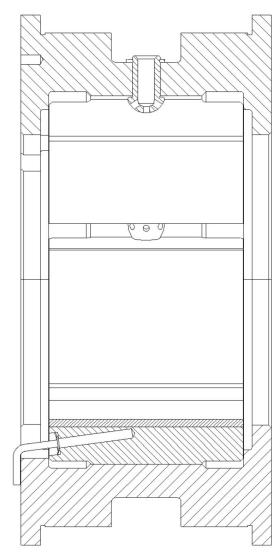

Figure 1. (a) Scheme and reference system of the bearing in nominal condition. Red dots represent the position of the temperature probe in each pad; (b) Actual drawings of the bearing.

The bearing model includes the equations for the equilibrium of pads and shaft, the 2D generalized Reynolds equation for the pressure distribution, a full 3D finite element thermal model composed of pads, oil-films and shaft and the finite element model for the mechanical and thermal deformation of the pads. 
Table 1. Bearing geometry in nominal condition.

\begin{tabular}{cc}
\hline Parameter & Value \\
\hline Number of pads & 5 \\
Shaft diameter & $100 \mathrm{~mm}$ \\
Bearing length & $70 \mathrm{~mm}$ \\
Assembled clearance & $60 \mu \mathrm{m}$ \\
Machined clearance & $130 \mu \mathrm{m}$ \\
Pad span angle & $60^{\circ}$ \\
Total pad thickness & $16 \mathrm{~mm}$ \\
Lining thickness & $2 \mathrm{~mm}$ \\
Oil type & ISO VG 46 \\
Oil inlet temperature & $40^{\circ}$ \\
Supply flow rate & $3 \mathrm{~L} / \mathrm{min}$ \\
Nominal speed & $3000 \mathrm{rpm}$ \\
Nominal specific load & $1.42 \mathrm{MPa}$ \\
Nominal load & $10 \mathrm{kN}$ \\
\hline
\end{tabular}

\subsection{Oil-Film Forces and Pressure Distribution}

The vector of the degrees of freedom of the system is given as follows:

$$
\mathbf{w}=\left[\begin{array}{lllll}
X_{S} & Y_{s} & \theta_{1} & \ldots & \theta_{N}
\end{array}\right]
$$

where $X_{s}$ and $Y_{s}$ represent the shaft centre position, $\theta_{k}$ represents the tilt angle of the $k$-th pad and $N$ is the number of pads. The equilibrium position of the system is given by the equilibrium of the oil-film forces on each pad and shaft.

In static conditions, the equilibrium of each pad is reached when the moment $\mathbf{M}_{k}$ of the oil-film forces $\mathbf{f}_{\text {oil }, k}$ w.r.t. the pivot is null, whereas the equilibrium of the shaft is obtained when the resultant of the oil-film forces of all the pads balances the load $\mathbf{W}$ on the shaft:

$$
\begin{gathered}
\mathbf{M}_{k}=\mathbf{b}_{k} \times \mathbf{f}_{\mathrm{oil}, k}=0 \\
\sum_{k=1}^{N} \mathbf{f}_{\mathrm{oil}, k}+\mathbf{W}=0
\end{gathered}
$$

The oil-film forces acting on each pad are obtained by integrating the oil-film pressure and shear stresses distributions. The $2 \mathrm{D}$ pressure distribution is obtained by means of the generalized Reynolds equation that takes into account the variation of viscosity and mass density in the direction of oil thickness. The generalized form of Reynolds equation is used instead of its classical form due to availability of the 3D temperature distribution, and therefore of the 3D distribution of viscosity and density, provided by the 3D thermal model. In stationary conditions the generalized Reynolds equation is as follows [20]:

$$
\begin{aligned}
& \frac{\partial}{\partial x}\left(M_{2} \frac{\partial p}{\partial x}\right)+\frac{\partial}{\partial z}\left(M_{2} \frac{\partial p}{\partial z}\right)=h\left[\frac{\partial(\rho u)_{2}}{\partial x}+\frac{\partial(\rho w)_{2}}{\partial z}\right]+ \\
& \quad-\frac{\partial}{\partial x}\left[\frac{M_{1}\left(u_{1}-u_{2}\right)}{F_{0}}+h \rho_{2} u_{2}-M_{3} u_{1}\right]+ \\
& \quad-\frac{\partial}{\partial z}\left[\frac{M_{1}\left(w_{1}-w_{2}\right)}{F_{0}}+h \rho_{2} w_{2}-M_{3} w_{1}\right]+\left[(\rho v)_{2}-(\rho v)_{1}\right]
\end{aligned}
$$

where

$$
\begin{aligned}
& M_{1}=\int_{0}^{h} \rho\left(\int_{0}^{y} \frac{d y^{\prime}}{\mu}\right) d y \\
& M_{2}=\frac{F_{1} M_{1}}{F_{0}}-\int_{0}^{h} \rho\left(\int_{0}^{y} \frac{y^{\prime} d y^{\prime}}{\mu}\right) d y \\
& M_{3}=\int_{0}^{h} \rho d y \\
& F_{0}=\int_{0}^{h} \frac{d y}{\mu} \\
& F_{1}=\int_{0}^{h} \frac{y d y}{\mu}
\end{aligned}
$$

$x$ is the tangential direction, $z$ is the axial direction, $y$ is the thickness direction, $h$ is the oil-film thickness, $p$ is the pressure in the oil-film, $\mu$ is the dynamic viscosity of the oil 
and $\rho$ is the mass density of the oil. The velocity vector components of the shaft and the pads are described by $u_{1}, v_{1}, w_{1}$ and $u_{2}, v_{2}, w_{2}$, respectively, where $u$ represents the velocity component along the tangential direction ( $x$ coordinate), $v$ the velocity component along the radial direction ( $y$ coordinate) and $w$ the velocity component along the axial direction ( $z$ coordinate).

\subsection{Thermal Model}

The dynamic viscosity $\mu$ and the mass density $\rho$ of the oil in Equation (1) are assumed to be functions of the temperature $T$ only, neglecting the dependency on pressure and shear rate, as follows:

$$
\begin{gathered}
\mu(T)=\mu_{400^{\circ} \mathrm{C}} \mathrm{e}^{-\kappa\left(T-T_{40}{ }^{\circ} \mathrm{C}\right)} \\
\rho(T)=\rho_{40^{\circ} \mathrm{C}}\left[1-\alpha_{v}\left(T-T_{40} \mathrm{C}\right)\right]
\end{gathered}
$$

where $\kappa$ and $\alpha_{v}$ are the viscosity index and the coefficient of thermal expansion of the oil, respectively.

The temperature distribution in the entire bearing is obtained by a three-dimensional thermal model that includes a portion of the shaft, the oil-films and the pads. In this way it is possible to simulate a more realistic heat exchange, where the heat generated in the oil-film due to viscous stresses is also dissipated by the shaft and the pads.

The energy equation of each oil-film, assuming laminar flow, is as follows:

$$
\rho c_{p}\left(u \frac{\partial T}{\partial x}+v \frac{\partial T}{\partial y}+w \frac{\partial T}{\partial z}\right)=k_{O I L}\left(\frac{\partial^{2} T}{\partial x^{2}}+\frac{\partial^{2} T}{\partial y^{2}}+\frac{\partial^{2} T}{\partial z^{2}}\right)+\mu\left[\left(\frac{\partial u}{\partial y}\right)^{2}+\left(\frac{\partial w}{\partial y}\right)^{2}\right]
$$

where $k_{O I L}$ and $c_{p}$ are the thermal conductivity and the heat capacity of the oil, respectively. Heat conduction, at steady state, only occurs in the shaft and the pads:

$$
\begin{gathered}
\nabla\left(k_{S H A F T} \nabla T\right)=0 \\
\nabla\left(k_{P A D, k} \nabla T\right)=0
\end{gathered}
$$

where $k_{S H A F T}$ and $k_{P A D, k}$ are the thermal conductivity coefficients of the shaft and the pad, respectively.

Equations (6) and (7) were solved by means of a finite element method, which mesh is shown in Figure 2.

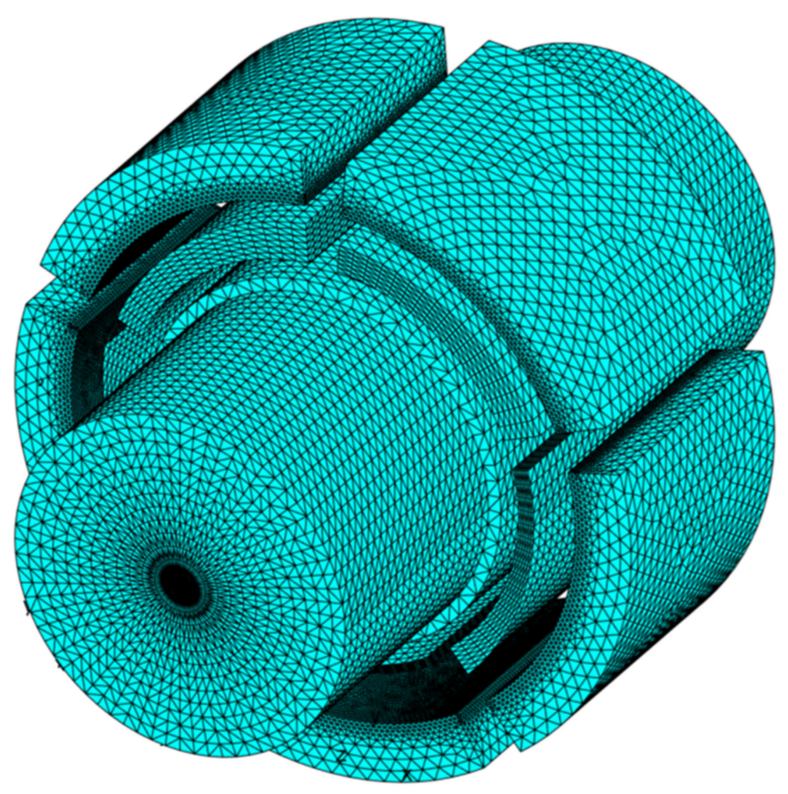

Figure 2. Mesh of the thermal model. Oil-film parts are magnified in the figure. 
Convective boundary conditions with the convection coefficients $q_{\text {oil }}=50 \mathrm{~W} / \mathrm{m}^{2} . \mathrm{K}$ for all the surfaces in contact with the lubricating oil at supply temperature of $T_{\text {supply }}=40{ }^{\circ} \mathrm{C}$ and $q_{\text {air }}=20 \mathrm{~W} / \mathrm{m}^{2} . \mathrm{K}$ for the surfaces of the two portions of the shaft in contact with the air at room temperature $T_{\text {room }}=30^{\circ} \mathrm{C}$ have been assumed. More details about the thermal model can be found in [21].

The inlet temperature of the lubricant flowing in the leading edge of each pad to be applied as boundary condition for the solution of Equation (6), is given by the mixing that occurs in the groove of two adjacent pads between the cold oil supplied at temperature $T_{\text {supply }}$ by the oil-nozzle and the hot oil at temperature $T_{\text {out }}^{k-1}$ from the previous pad.

In the mixing model it is assumed that the known total supplied flow rate in the bearing $\dot{m}_{\text {Supply }}^{T O T}$ is equally distributed on the pads, i.e., $\dot{m}_{\text {Supply }}^{k}=\dot{m}_{\text {Supply }}^{T O T} / N$.

Considering the mass balance and energy equations for the $k$-th groove and the $k$-th pad, the inlet temperature of the $k$-th pad can be obtained as follows:

$$
T_{\text {in }}^{k}=\frac{\left(\dot{m} c_{p}\right)_{\text {out }}^{k-1} T_{\text {out }}^{k-1}+\left[\left(\dot{m} c_{p}\right)_{\text {Supply }}^{k-1}-\beta \cdot\left(\dot{m} c_{p}\right)_{\text {Leak Groove }}^{k-1}\right] T_{\text {supply }}}{(1-\beta)\left(\dot{m} c_{p}\right)_{\text {Leak Groove }}^{k-1}+\left(\dot{m} c_{p}\right)_{\text {in }}^{k-1}}
$$

where $\beta$ is the mixing coefficient defined as follows [21]:

$$
\beta=1-\frac{\dot{m}_{\text {out }}^{k-1}}{\dot{m}_{\text {Supply }}^{k}}
$$

When a large amount of cold supplied oil is fed into the groove $\dot{m}_{\text {Supply }}^{k} \gg \dot{m}_{\text {out }}^{k-1}$, $\beta \approx 1$, which means that the oil entering the $k$-th pad is not affected by the hot oil coming from the previous pad. Perfect mixing occurs when $\dot{m}_{\text {Supply }}^{k} \approx \dot{m}_{\text {out }}^{k-1}$.

\subsection{Pad Deformation}

The deformation of the pad (displacement $\mathbf{u}$ ) due to thermal and mechanical stresses is governed by the elasticity equation:

$$
\nabla \cdot(C \otimes \nabla \mathbf{u})=\frac{E}{1-2 v} \alpha \nabla T
$$

where $C$ is the tensor of mechanical properties, $\alpha$ is the thermal expansion coefficient, $E$ is Young's modulus, and $v$ is Poisson's ratio of the material.

Equation (10) has been solved using a finite element model, which tetrahedral mesh is shown in Figure 3.

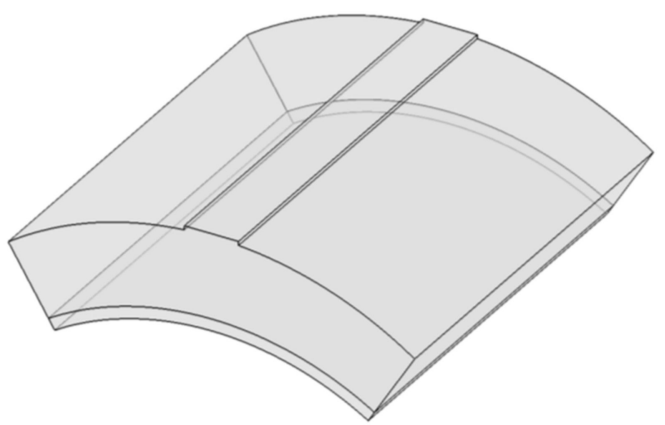

(a)

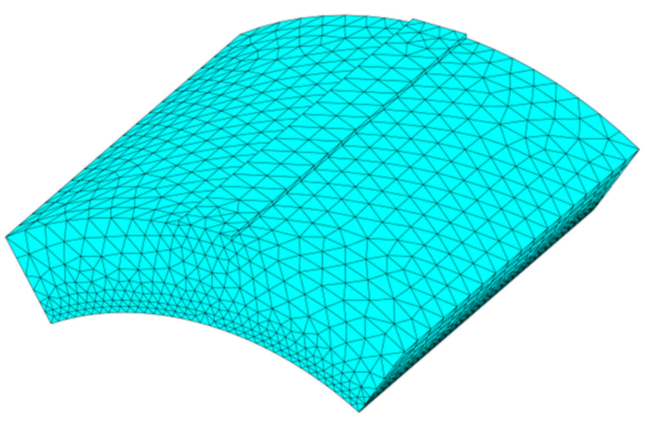

(b)

Figure 3. (a) Pad solid model and (b) mesh.

As boundary conditions, a null displacement has been assumed for the surface of the pad corresponding to the pivot part. The pressure and the shear fields obtained from the Reynolds equation have been applied to the active surface of the pad. 
The resultant deformation of the pad surface has been then transformed in the change of oil-film thickness.

\section{Results and Discussion}

In this section the static behaviour of the bearing for two lining material will be investigated. Standard Babbitt alloy (SnSb8Cu4, ASTM B-23 \#2) and high performance thermoplastic $20 \%$ carbon fibre reinforced PEEK will be considered for the lining and S355 steel for the back of the pad. The mechanical and thermal properties of these materials are listed in Table 2.

Table 2. Material properties.

\begin{tabular}{cccc}
\hline Parameter & Steel & Babbitt & PEEK \\
\hline Young modulus [GPa] & 210 & 56.5 & 19.5 \\
Poisson's ratio & 0.3 & 0.35 & 0.35 \\
Yield point $20^{\circ} \mathrm{C}[\mathrm{MPa}]$ & 355 & 46 & 170 \\
Yield point $100^{\circ} \mathrm{C}[\mathrm{MPa}]$ & 355 & 20.6 & 80 \\
Thermal expansion coefficient $[\mu \mathrm{m} / \mathrm{m} . \mathrm{K}]$ & 12 & 23.4 & 8 \\
Heat conductivity $[\mathrm{W} / \mathrm{m} . \mathrm{K}]$ & 45 & 55 & 0.43 \\
Melting temperature $\left[{ }^{\circ} \mathrm{C}\right]$ & & 233 & 343 \\
\hline
\end{tabular}

In Table 2, it is interesting to note the halving of the yield point from $20^{\circ} \mathrm{C}$ to $100{ }^{\circ} \mathrm{C}$ for the two lining materials.

Firstly, the static behaviour of the bearing with Babbitt and PEEK lining will be investigated in nominal conditions of load $(10 \mathrm{kN})$, speed $(3000 \mathrm{rpm})$ and lining thickness $(2 \mathrm{~mm})$. Then the analysis of the effect of the lining thickness on the static behaviour of the bearing will be shown in the nominal condition of load $(10 \mathrm{kN})$ and speed $(3000 \mathrm{rpm})$. Eventually, the operating range of the bearing for the nominal lining thickness $(2 \mathrm{~mm})$ will be further analysed.

\subsection{Bearings in Nominal Conditions}

The temperature distributions and the pad deformation in the middle cross-section of the entire bearing system for the Babbitt and PEEK lining are shown in Figures 4 and 5, respectively. The values of the maximum temperature in the oil-films, the temperature measured by the temperature probe as well as other characteristic quantities are listed in Table 3. In general, better values of oil-film pressure, thickness, temperature, von Mises stress and radial deformation are obtained in nominal conditions for the bearing with the Babbitt lined pads.

The thermal insulation properties of the PEEK lining results in a higher oil-film temperature due to the reduction of the heat exchanges between the lateral surfaces of the steel part of the pads and the surroundings, and a lower probe temperature than that obtained in the bearing with Babbitt lining.

It is interesting to note that the temperature gradient in the pads is mainly along the tangential direction for the Babbitt lining due to the similar thermal conductivity of Babbitt and steel materials as depicted in Table 2. Conversely, the temperature gradient is mainly in the radial direction for the PEEK lining. This different thermal behaviour results in a main thermal expansion in the tangential direction for the pad with the Babbitt lining due to the similar thermal expansions of the steel base and lining parts. Conversely in the pad with PEEK lining, the steel base has a lower thermal expansion, resulting in a bending deformation of the pad about the pivot. This is true under the model assumption of a perfect bonding of the linings on the steel base. Therefore, for the PEEK case, even if the steel part of the pad is colder with respect to the Babbitt case, higher deformations in the radial direction as well as higher maximum von Mises stress occurred in the lining. 

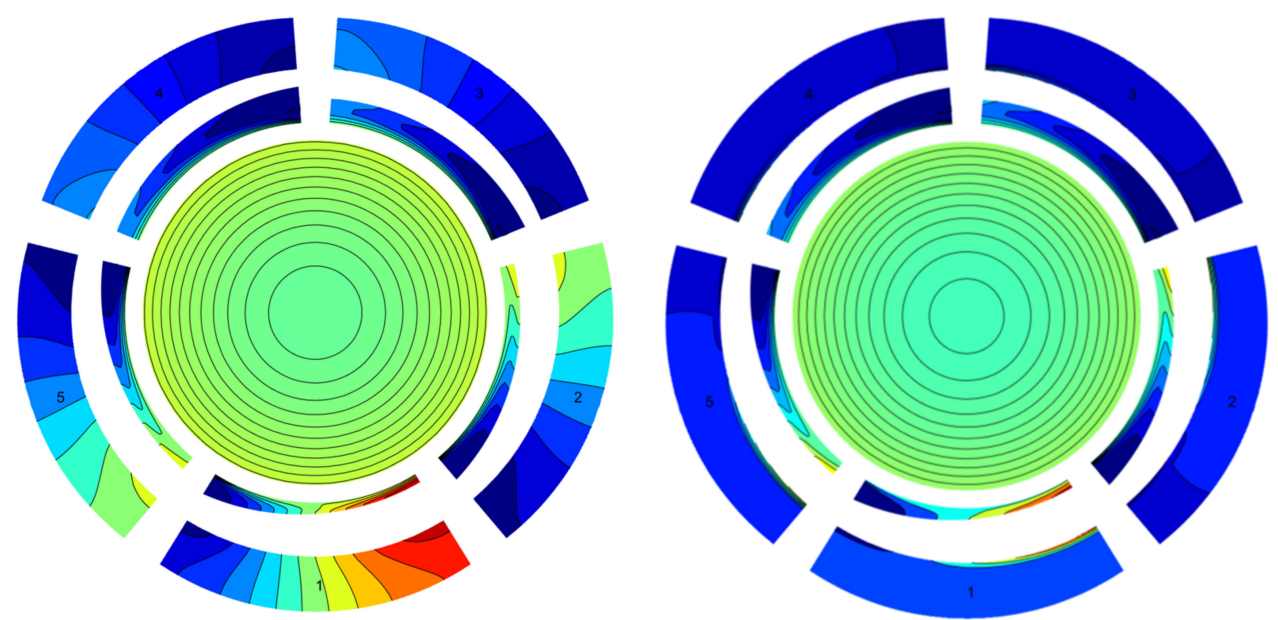

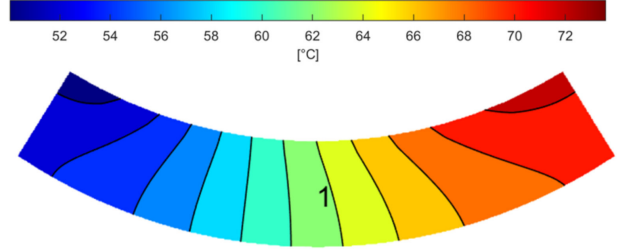

(a)

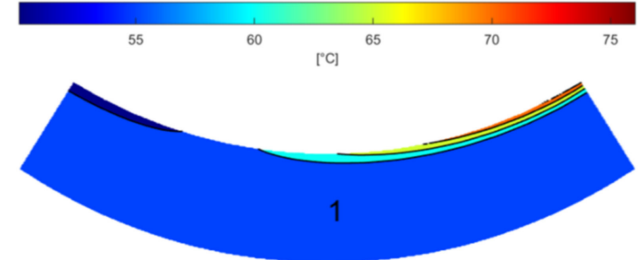

(b)

Figure 4. Temperature distribution in nominal conditions: (a) Babbitt lining and (b) PEEK lining.
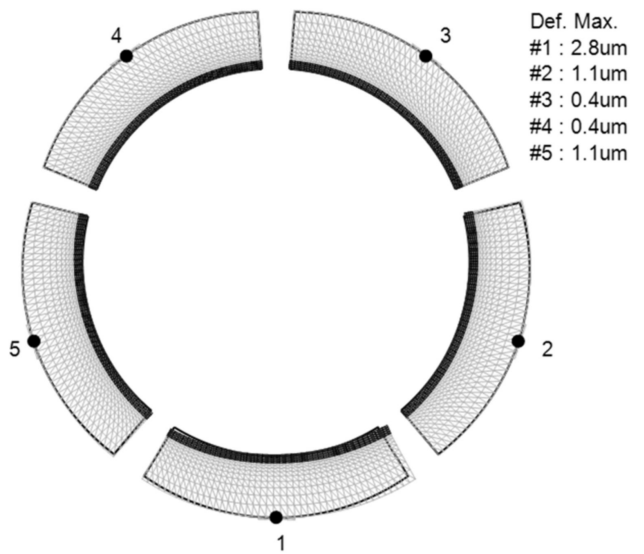

(a)
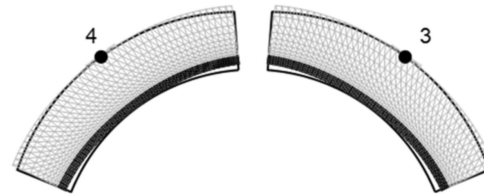

Def. Max.

$\# 1$ : 9.5 um $\# 2: 7.2 \mathrm{um}$ $\# 3: 5.5 \mathrm{um}$ $\# 5: 6.1$ um

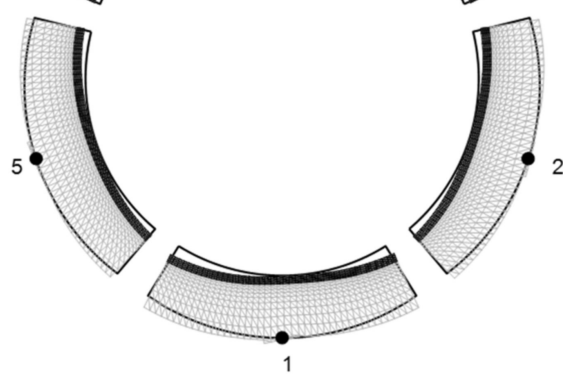

(b)

Figure 5. Pad deformation in nominal conditions: (a) Babbitt lining and (b) PEEK lining.

Table 3. Results of simulation in nominal conditions.

\begin{tabular}{ccc}
\hline Parameter & Babbitt & PEEK \\
\hline Max. oil-film temperature $\left[{ }^{\circ} \mathrm{C}\right]$ & 73.6 & 76.2 \\
Probe temperature $\left[{ }^{\circ} \mathrm{C}\right]$ & 63.6 & 57.8 \\
Max. von Mises stress $($ lining) $[\mathrm{MPa}]$ & 15.7 & 35.4 \\
Max. radial deformation $($ lining) $[\mu \mathrm{m}]$ & 2.8 & 9.5 \\
Min. oil-film thickness $[\mu \mathrm{\mu m}]$ & 21.4 & 19.2 \\
Max. oil-film pressure $[\mathrm{MPa}]$ & 6.58 & 7.03 \\
\hline
\end{tabular}

The maximum deformation occurred in the loaded pad (Figure 5), where also the highest temperature occurred. In general, the pad deformation corresponds to an increase in the radius of curvature of the active surface of the pad. The deformation mainly occurred at the leading and trailing edges of the pad, while is quite negligible in the centre of the pad 
in which the thermal expansion in the radial direction is balanced by the lining compression due to the oil-film pressure. By approximating the deformed surface with a cylinder passing through the three points $k_{1}, k_{2}$ and $k_{3}$ as shown in the scheme of Figure $6 \mathrm{a}$, and considering the radial deformation $\Delta$ at the pad edges, the not negligible equivalent machined clearance $C_{p}=R_{\text {pad }}-R_{\text {shaft }}$ can be obtained (Figure $6 \mathrm{~b}$ ).

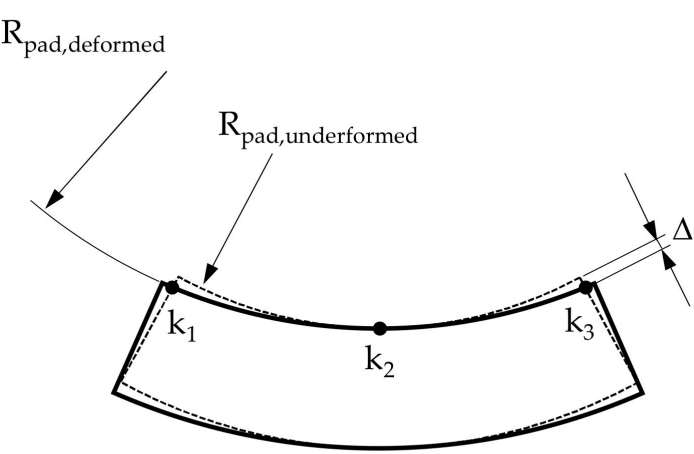

(a)

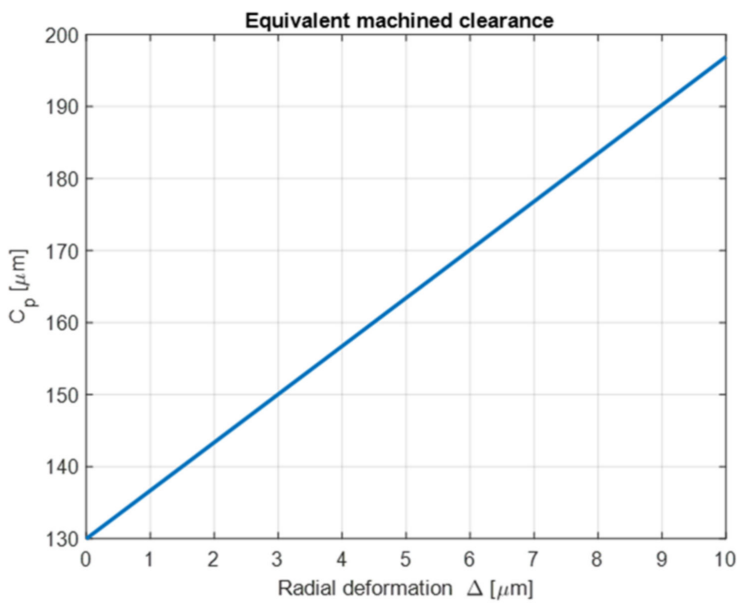

(b)

Figure 6. (a) Fitting of pad surface deformation; (b) equivalent machined clearance.

\subsection{Lining Thickness}

In this section the effect of the lining thickness will be investigated in the range of $1-5 \mathrm{~mm}$. The base part of the pad is the same for all the values of lining thickness, that is the thickness of the pad base is fixed and equal to $14 \mathrm{~mm}$. The base pad thickness value is obtained by subtracting the nominal lining thickness $(2 \mathrm{~mm})$ from the total pad thickness (16 mm, see Table 1). In this way, the variation of pad deformation and other quantities can be mainly ascribed to the variation of the lining thickness.

As shown in Figure 7, better values of oil-film pressure, thickness, temperature, von Mises stress and radial deformation are obtained for low value of the Babbitt lining thickness and large values of PEEK lining thickness.

The bearing behavior for the two lining materials is different. For example, with the increase in the lining thickness, the maximum pressure increases for the Babbitt lining whereas decreases for the PEEK lining. This behavior is consistent with results published in [18].

This opposite behaviour is due to the different thermal distributions of Babbitt and PEEK-lined pads that result in a different pad deformation for the two lining materials.

It happens that the maximum radial deformation in the lining is higher for the PEEK but decreases with the increase in the lining thickness whereas slightly increases for the Babbitt.

In general, the effect of an increase in the radial deformation is an average increase in the machined clearance or in the preload factor as shown in Figure $6 b$.

For TPJBs, by increasing the machined clearance or the preload factor, the pressure increases in the oil-film. Therefore the trends for an increase in the lining thickness are:

- $\quad$ PEEK: decrease in radial deformation $\rightarrow$ decrease in machined clearance $\rightarrow$ decrease in the oil-film pressure.

- $\quad$ BABBIT: increase in radial deformation $\rightarrow$ increase in machined clearance $\rightarrow$ increase in the oil-film pressure 

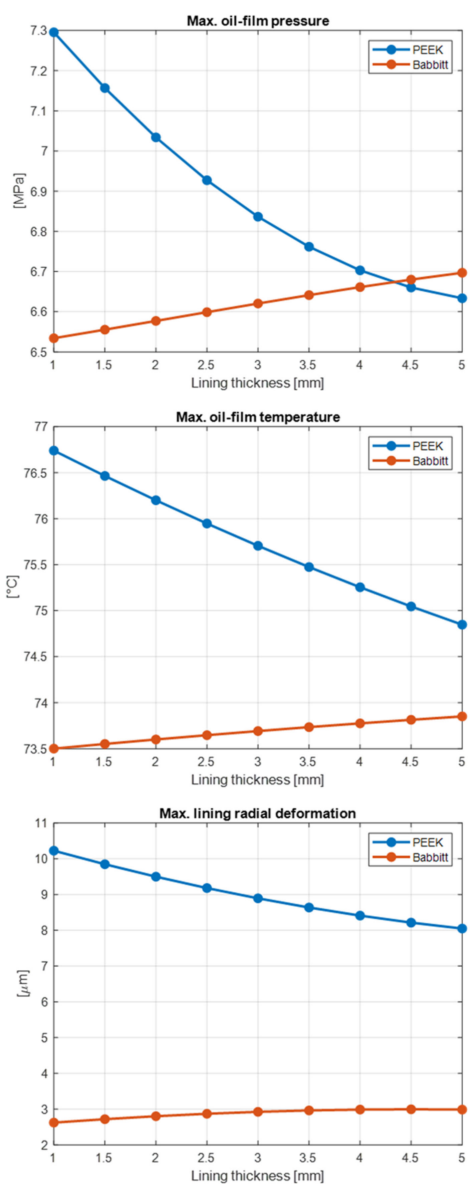
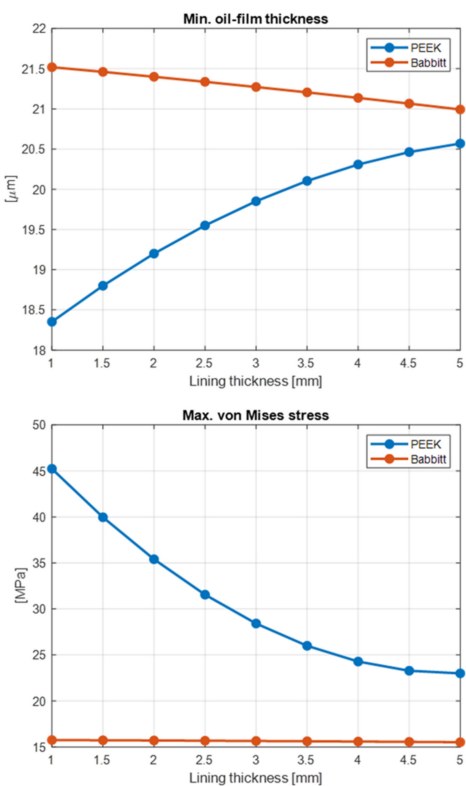

Figure 7. Results of the analysis on the lining thickness.

\subsection{Operating Range}

From the previous analyses it results that better performances are obtained by the standard Babbitt lining than the more advanced PEEK material. Therefore, a further analysis is conducted by exploring more severe operating conditions in terms of load and speed where PEEK lining can offer better performance. The operating range of the bearing will be analysed for variation of specific load in the range 0.5-2.5 $\mathrm{MPa}$ and shaft speed in the range 1000-5000 rpm. The same lining thickness of $2 \mathrm{~mm}$ is considered in this analysis. The maps of maximum temperature, minimum oil-film thickness, maximum von Mises stress and maximum radial deformation are shown in Figure 8.

In general, the maps of the maximum oil-film temperature, minimum oil-film thickness and maximum von Mises stress are quite the same for the two lining materials. The main difference between the two material can be highlighted in the maximum radial deformation, that mainly increases only with the load for the Babbitt lining and increases both with the load and speed for the PEEK lining. Also in this case, better performance is obtained in the considered operating range by the Babbitt lining. Anyway the value of the maximum von Mises stress $\sigma_{V M \text {,max }}$ must be compared to the yield stress $R_{p 0.2}$ that indicates the limit of the elastic behavior of the material. As already discussed, the yield point value strongly decreases with the temperature. A halving of the yield stress roughly occurred from $20{ }^{\circ} \mathrm{C}\left(R_{p} 0.2,20^{\circ} \mathrm{C}\right)$ and $100{ }^{\circ} \mathrm{C}$ as shown in Table 2 for both the two lining materials. The reduction of the yield point with the temperature can be approximated with a linear function as follows:

$$
R_{p 0.2}(T)=R_{p 0.2,20^{\circ} \mathrm{C}}\left[1-k_{p 0.2} \cdot\left(T-20^{\circ} \mathrm{C}\right)\right]
$$



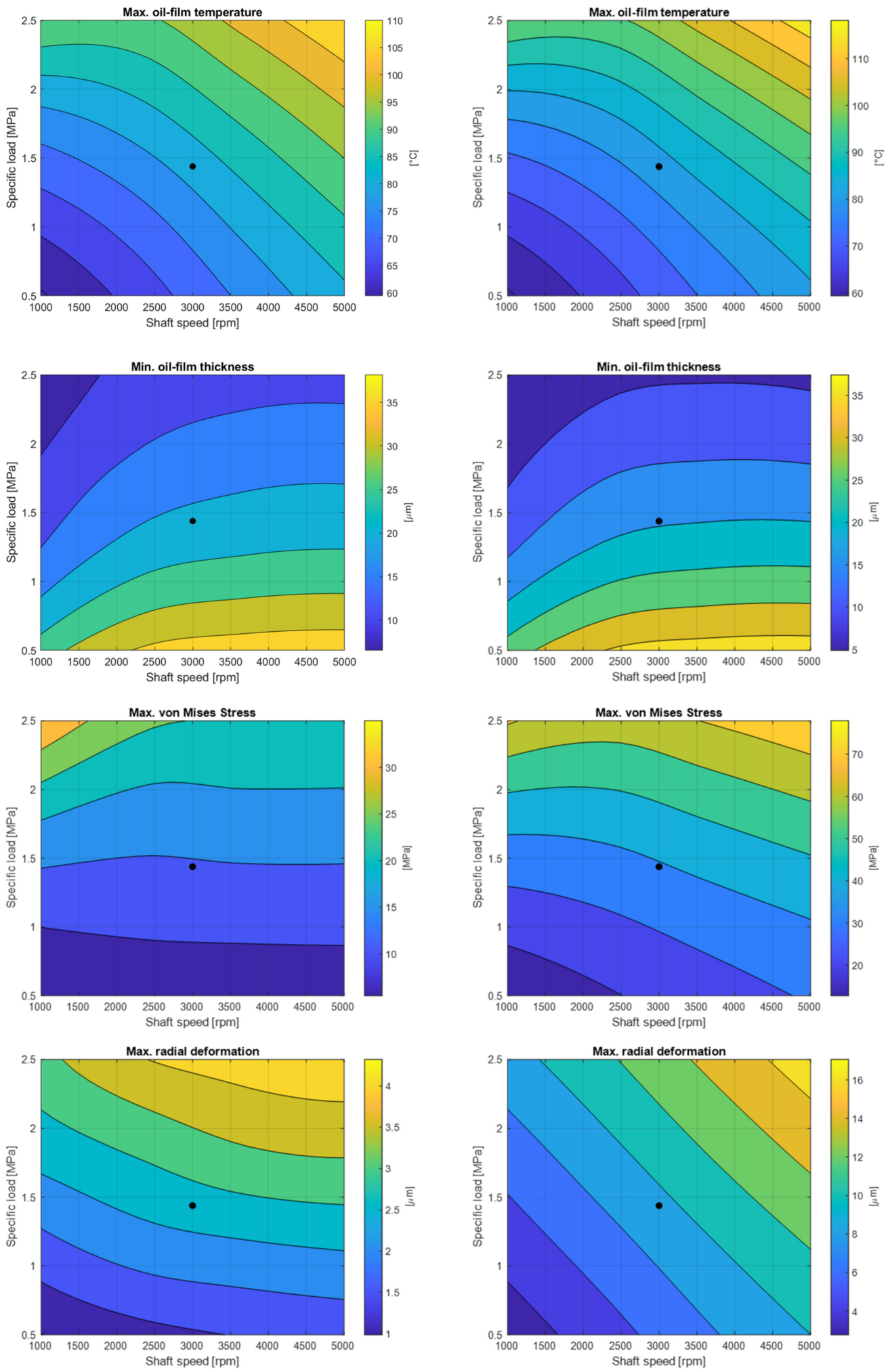

(a)

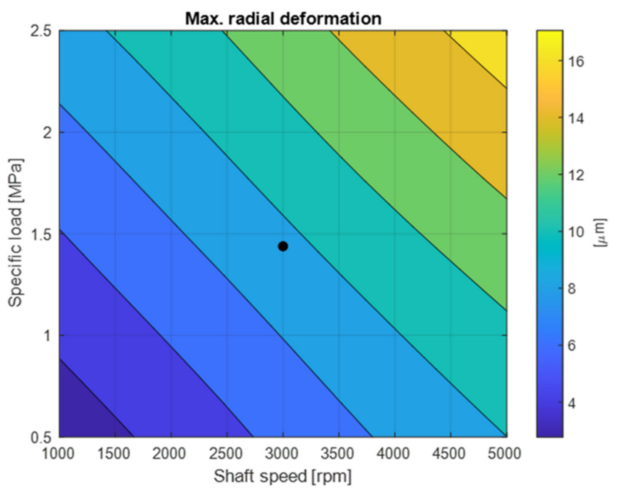

(b)

Figure 8. Maps of maximum temperature, minimum oil-film thickness, maximum von Mises stress and maximum radial deformation. (a) Babbitt lining and (b) PEEK lining. 
In this way, by considering the map of the maximum temperature, it is possible to evaluate the stress coefficient $\eta$ given by the ratio between the maximum von Mises stress $\sigma_{V M, \max }$ and the local yield stress $R_{p} 0.2(T)$ as follows:

$$
\eta=\frac{\sigma_{V M, \max }}{R_{p 0.2}(T)}
$$

Without entering in the details of the creep mechanism a value of the stress coefficient higher than 1 means that plastic deformation certainly occurs in the material.

The maps of the stress coefficient are shown in Figure 9, where three regions with limits on the stress coefficient at $50 \%$ and $100 \%$ can be assumed for the definition of the operating range of the bearing, where in the red region plastic deformation occurred and the green region represent the safe region with a stress coefficient lower than $50 \%$.

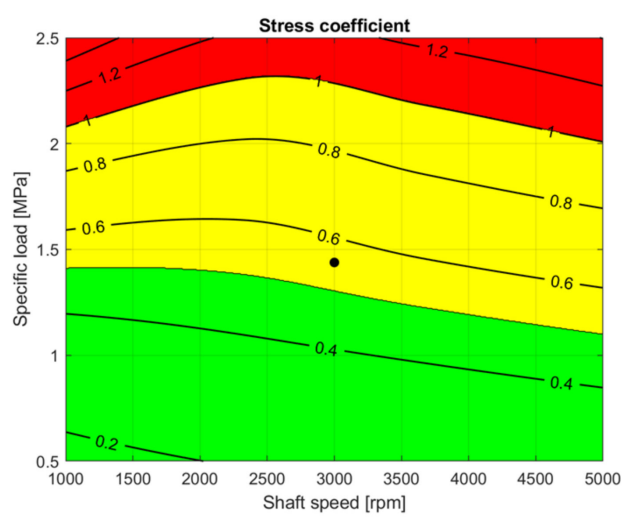

(a)

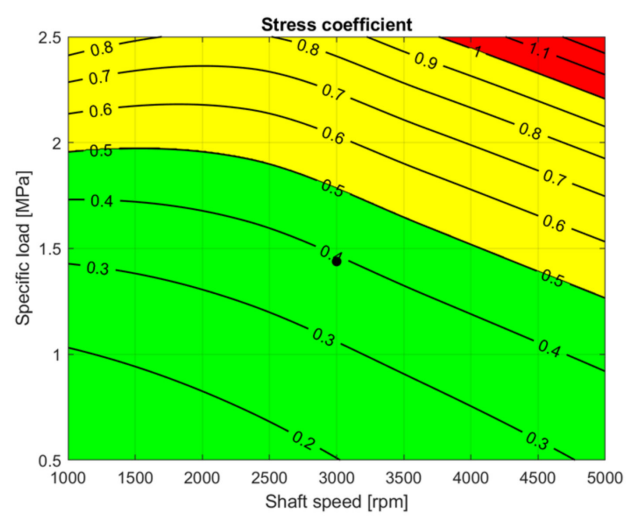

(b)

Figure 9. Operating range: (a) Babbitt lining and (b) PEEK lining.

From the comparison of the stress coefficient maps, it results that the PEEK lining allows the operating range of the bearing to be extended.

\section{Conclusions}

In the paper the behavior of bearings with Babbitt and PEEK lining has been compared. In general, the bearing with Babbitt lining shows better results than the PEEK lining in terms of typical oil-film quantities such as maximum temperature, maximum pressure and minimum thickness. The main difference arises in the temperature distribution in the pad where the thermal insulating properties of the PEEK lining results in a higher deformations of the pad. Nevertheless, the higher yield point of the PEEK allows to extend the operating range of bearing. The analysis also suggested the reduction of the lining thickness for the Babbitt lining and the increase of the lining thickness for the PEEK lining.

The coating thickness analysis results for a fixed pad base part thickness suggest further investigation of the coating thickness with a fixed total pad thickness considering either a constant coating thickness or a non-uniform coating thickness.

For PEEK-coated pads the problem of the large difference between the values of the temperature measured by the temperature probe and the actual temperature of the oil filter is very evident. Therefore, for these bearings, the temperature probe signal cannot be used as an alarm of the reduction of the load bearing capacity. An alternative method of measuring the temperature in the oil film or the use of a different quantity as an indicator of the reduction in the bearing capacity has to be developed.

Eventually, the behaviour of PEEK lined pads will be investigated by experimental test in future work. 


\begin{abstract}
Author Contributions: Conceptualization, S.C.; methodology, S.C. and A.V.; software, S.C., E.G. and P.V.D.; validation, S.C.; formal analysis, S.C.; investigation, S.C. and E.G.; resources, P.P.; data curation, S.C.; writing-original draft preparation, S.C.; writing-review and editing, P.V.D., P.P. and E.G.; visualization, S.C.; supervision, P.P.; project administration, S.C.; funding acquisition, P.P. All authors have read and agreed to the published version of the manuscript.
\end{abstract}

Funding: This research received no external funding.

Institutional Review Board Statement: Not applicable.

Informed Consent Statement: Not applicable.

Data Availability Statement: Not applicable.

Acknowledgments: We acknowledge Davide Scaglia (Eurobearings S.r.l.) for providing bearing data and lining material properties.

Conflicts of Interest: The authors declare no conflict of interest.

\title{
References
}

1. Tauviqirrahmana, M.; Pratamaa, A.; Jamaria, M. Hydrodynamic Lubrication of Textured Journal Bearing Considering Slippage: Two-dimensional CFD Analysis Using Multiphase Cavitation Model. Tribol. Ind. 2019, 41, 401-415. [CrossRef]

2. Kuznetsov, E.; Glavatskih, S. Dynamic characteristics of compliant journal bearings considering thermal effects. Tribol. Int. 2016, 94, 288-305. [CrossRef]

3. Zhang, F.; Ouyang, W.; Hong, H.; Guan, Y.; Yuan, X.; Dong, G. Experimental study on pad temperature and film thickness of tilting-pad journal bearings with an elastic-pivot pad. Tribol. Int. 2015, 88, 228-235. [CrossRef]

4. Zulhanafi, P.; Syahrullail, S.; Ahmad, M.A. The Tribological Performance of Hydrodynamic Journal Bearing Using Bio-based Lubricant. Tribol. Ind. 2020, 42, 278-287. [CrossRef]

5. Dang, P.V.; Chatterton, S.; Pennacchi, P.; Vania, A. Numerical investigation of the effect of manufacturing errors in pads on the behaviour of tilting-pad journal bearings. J. Eng. Tribol. 2018, 232, 480-500. [CrossRef]

6. Yang, J.; Palazzolo, A. Three-Dimensional Thermo-Elasto-Hydrodynamic Computational Fluid Dynamics Model of a Tilting Pad Journal Bearing-Part I: Static Response. J. Tribol. 2019, 141, 61702. [CrossRef]

7. Yang, J.; Palazzolo, A. Computational Fluid Dynamics Based Mixing Prediction for Tilt Pad Journal Bearing TEHD Modeling-Part I: TEHD-CFD Model Validation and Improvements. J. Tribol. 2021, 143, 11601. [CrossRef]

8. Chatterton, S.; Pennacchi, P.; Vania, A.; Dang, P.V. Optimization of an Oil-film Journal Bearing for Temperature Reduction. In Proceedings of the ASME Turbo Expo 2021, Virtual, 7-11 June 2021; Volume 9A. [CrossRef]

9. Chatterton, S.; Pennacchi, P.; Vania, A.; De Luca, A.; Dang, P.V. Tribo-Design of Lubricants for Power Loss Reduction in the Oil-Film Bearings of a Process Industry Machine: Modelling and Experimental Tests. Tribol. Int. 2019, 130, 133-145. [CrossRef]

10. Yang, J.; Palazzolo, A. Power Loss Reduction for Tilt Pad Journal Bearings Utilizing Pad Pockets and Steps. Tribol. Int. 2021, 159, 106993. [CrossRef]

11. Lan, P.; Meyer, J.L.; Vaezian, B.; Polycarpou, A.A. Advanced Polymeric Coatings for Tilting Pad Bearings with Application in the Oil and Gas Industry. Wear 2016, 354-355, 10-20. [CrossRef]

12. Desvaux, M.P.E. Development of a High-Tin Aluminium Plain Bearing Material. Tribology 1972, 5, 61-66. [CrossRef]

13. Wang, J.M.; Xue, Y.W.; Li, W.H.; Wei, A.Z.; Cao, Y.F. Study on Creep Characteristics of Oil-film Bearing Babbitt. Mater. Res. Innov. 2014, 18, S2-S16. [CrossRef]

14. Mironov, A.; Gershman, I.; Gershman, E.; Podrabinnik, P.; Kuznetsova, E.; Peretyagin, P.; Peretyagin, N. Properties of Journal Bearing Materials That Determine Their Wear Resistance on the Example of Aluminum-Based Alloys. Materials 2021, 14, 535. [CrossRef] [PubMed]

15. Koosha, R.; San Andrés, L. Effect of Pad and Liner Material Properties on the Static Load Performance of a Tilting Pad Thrust Bearing. J. Eng. Gas Turbines Power 2019, 141, 121007. [CrossRef]

16. Zhou, J.; Bearings, W. Temperature Monitoring of PEEK Bearings. In Proceedings of the "Society of Tribologists and Lubrication Engineers Annual Meeting and Exhibition 2016", Las Vegas, NV, USA, 15-19 May 2016; pp. 175-192.

17. Stottrop, M.; Bender, B. Mechanical and Thermal Deformation Analysis of a Large Polymer Lined Tilting Pad Journal Bearing. In Proceedings of the ASME Turbo Expo 2021, Virtual, 7-11 June 2021; Volume 9A. [CrossRef]

18. Cha, M.; Isaksson, P.; Glavatskih, S. Influence of pad compliance on nonlinear dynamic characteristics of tilting pad journal bearings. Tribol. Int. 2013, 57, 46-53. [CrossRef]

19. Simmons, G.F.; Varela, A.C.; Santos, I.F. Dynamic characteristics of polymer faced tilting pad journal bearings. Tribol. Int. 2014, 74, 20-27. [CrossRef]

20. Fowles, P.E. A Simpler Form of the General Reynolds Equation. J. Lubr. Technol. 1970, 92, 661-662. [CrossRef]

21. Chatterton, S.; Pennacchi, P.; Vania, A.; Dang, P.V. Cooled Pads for Tilting-Pad Journal Bearings. Lubricants 2019, 7, 92. [CrossRef] 